\title{
Penerapan Metode Servqual Dalam Menentukan Tingkat Kepuasan Masyarakat Terhadap Pelayanan Pengurusan Surat Izin Usaha Mikro Dan Kecil Pada Kantor Camat Dolat Rayat Kabupaten Karo
}

\author{
Junius Sembiring ${ }^{1 *}$, Bosker Sinaga $^{2}$ \\ ${ }^{1,2}$ STMIK Pelita Nusantara \\ Jl. Iskandar Muda No. 1 Medan 20154 Indonesia \\ Corresponding author's e-mail: juniussembiring84@gmail.com
}

\begin{abstract}
Abstrak - Adanya permasalahan yang dihadapai masyarakat adalah masyarakat tidak bisa memberikan penilaian kepuasan terhadap pengurusan izin uasaha mikro dan kecil, hal ini membuat pegawai tidak bias mengukur kepuasan masyarakat untuk meningkatkan kualitas pelayanan di kantor camat. Dalam mengambil keputusan diperlukan sebuah sistem yang dapat menentukan tingkat kepuasan masyarakat berdasarkan kriteria yang ditentukan oleh pengguna. Penerapan Metode Servqual Dalam Menentukan Tingkat Kepuasan Masyarakat Terhadap Pelayanan Pengurusan Surat Izin Usaha Mikro Dan Kecil Pada Kantor Camat Dolat Rayat Kabupaten Karo. Metode Servqual adalah suatu kuesioner yang dapat mengukur kualitas jasa. Metode ini digunakan untuk mengukur kualitas layanan dari atribut masing-masing dimensi, sehingga akan diperoleh nilai gap (kesenjangan) yang merupakan selisih antara persepsi konsumen terhadap layanan yang diterima. Metode Servqual memiliki dua perspektif internal dan perspektif eksternal. Perspektif internal didefenisikan dengan bebas kesalahan (zero defect) sedangkan perspektif eksternal digunakan untuk memahami apa yang diharapkan konsumen, dirasakan konsumen dan kepuasan konsumen.
\end{abstract}

Kata kunci: Pelayanan, Kepuasan Masyarakat, Penilaian, Metode Servqual

Abstract - There is a problem faced by the community is that the community cannot provide an assessment of satisfaction with the management of micro and small business permits, this makes employees not biased to measure community satisfaction to improve service quality in the camat office. In making decisions, we need a system that can determine the level of community satisfaction based on criteria determined by the user. Application of the Servqual Method in Determining the Level of Community Satisfaction with Services for Managing Micro and Small Business Licenses at the Sub-District Office of Dolat Rayat, Karo Regency. The Servqual method is a questionnaire that can measure service quality. This method is used to measure the service quality of the attributes of each dimension, so that a gap value is obtained which is the difference between consumer perceptions of the services received. The Servqual method has two internal perspectives and an external perspective. The internal perspective is defined as being free of errors (zero defect), while the external perspective is used to understand what consumers expect, feel and customer satisfaction.

Keywords: Service, Community Satisfaction, Assessment, Servqual Method

\section{Pendahuluan}

Pelayanan adalah salah perbuatan untuk membantu orang lain dalam mengurus sesuatu yang dibutuhkan sesuai keperluan orang lain. Pelayanan pada umunya adalah suatu kegiatan yang sifatnya membantu orang lain untuk menyelesaikan permasalahan sesuai dengan yang dibutuhkan. Kepuasan masyarakat adalah salah satu perilaku yang membuat perasaan senang atau kecewa yang memiliki hasil dari perlakuan yang dirasakan dan diharapkan, tingkat kepuasan suatu pelayanan yang diberikan terhadap masyarakat tergantung dari seberapa baik pelayanan yang diberikan dan pelayanan tersebut dapat diterima oleh masyarakat [1]. Tingkat kepuasan masyarakat dapat di ukur dari seberapa banyak masyarakat yang tidak mengeluh akan pelayanan yang diberikan, sering terjadi permasalahan terhadap pelayanan yang diberikan sehingga masyarakat akan kecewa dengan pelayanan tersebut. Pelayanan yang kurang baik akan berdampak buruk bagi suatu instansi, lembaga dll maka dengan itu pelayanan harus ditingkatkan agar lebih baik lagi. Kepuasan kerja merupakan suatu istilah yang menyangkut aspek perasaan pekerja terhadap pekerjaannya [2]. Kepuasan kerja sebenarnya suatu keadaan yang sulit didefenisikan, meski dalam bentuk yang sederhana sekalipun. Suatu defenisi yang sederhana tentang kepuasan kerja, yaitu perasaan seseorang terhadap pekerjaannya. Konsepsi semacam ini melihat kepuasan sebagai suatu hasil dari interaksi manusia dan lingkungannya. Metode Servqual adalah suatu kuesioner yang digunakan untuk mengukur tingkat pelayanan yang diberikan. Adanya kuesioner dapat mengetahui seberapa besar celah (gap) yang ada di antara persepsi masyarakat dan ekspektasi masyarakat terhadap suatu perusahaan pelayanan [3].

Metode servqual adalah suatu kuesioner yang digunakan untuk mengukur kualitas jasa. Cara ini mulai 
dikembangkan pada tahun 1980-an oleh Zeithaml, Parasuraman \& Berry, dan telah digunakan dalam mengukur berbagai kualitas jasa. Dengan kuesioner ini, kita bisa mengetahui seberapa besar celah (gap) yang ada di antara persepsi masyarakat dan ekspektasi pelanggan terhadap suatu perusahaan jasa. Kuesioner servqual dapat diubah-ubah (disesuaikan) agar cocok dengan industri jasa yang berbeda-beda pula (misalnya bank, restoran, atau perusahaan telekomunikasi) [4]. Metode servqual memiliki dua perspektif yaitu perspektif internal dan perspektif eksternal. Perspektif eksternal digunakan untuk memahami apa yang diharapkan konsumen, dirasakan konsumen, dan kepuasan konsumen. Pengukurannya menggunakan metode servqul. Servqual adalah suatu peralatan untuk mengukur kualitas dari pelayanan oleh sebuah informasi dari penyedia pelayanan. Sedangkan, perspektif internal diidentifikasikan dengan bebas kesalahan (zero defect) dan melakukan dengan benar saat pertama kali serta menyesuaikan dengan permintaan [5]. Untuk mengukur perspektif internal yang bebas kesalahan (zero defect) yang berhubungan dengan kualitas pelayanan digunakan metode six sigma. Six sigma adalah seperangkat alat yang digunakan untuk mengidentifikasi, menganalisis, dan mengeliminasi sumber variasi dalam proses [6]. Kuesioner servqual dapat diubah-ubah (disesuaikan) agar cocok dengan industri jasa yang berbeda-beda pula (misalnya bank, restoran, atau perusahaan telekomunikasi) [7] Kualitas dapat dipegaruhi oleh cara pandang setiap orang yang bersifat subjektif. Kualitas dianggap ukuran relatif dari kebaikan sutau produk atau jasa. Kualitas pelayanan merupakan suatu pembahasan yang sangat kompleks karena penilaian kualitas pelayanan berbeda dengan penilaian terhadap suatu produk, terutama karena sifatnya yang tidak nyata (intangible) dan produksi serta konsumsi berjalan secara simultan. Disamping perbedaan karakteriktik ini, dalam penelitian kualitas pelayanan, konsumen terlibat langsung dalam proses jasa tersebut, sehingga yang dimaksud dengan kualitas pelayanan adalah bagaimana tanggapan konsumen terhadap jasa yang dikonsumsi atau yang dirasakan [8].

\section{Tinjauan Pustaka}

\subsection{Metode Servqual}

Metode Servqual merupakan metode yang digunakan untuk mengukur kualitas layanan dari atribut masingmasing dimensi, sehingga akan diperoleh nilai gap (kesenjangan) yang merupakam selisih antara persepsi konsumen terhadap layanan yang telah diterima dengan harapan terhadap yang akan diterima [9]. Pengukurannya metode ini dengan mengukur kualitas layanan dari atribut masing-masing dimensi, sehingga akan diperoleh nilai gap yang merupakan selisih antara persepsi konsumen terhadap layanan yang diterima dengan harapan konsumen terhadap layanan yang akan diterima. Skala servqual meliputi lima dimensi kualitas jasa yaitu; Tangibles, Reliability, Responsiveness, Assurance, dan Empathy. Setiap dimensi memiliki beberapa pertanyaan dan dijawab dalam rentang nilai 1 sampai 7, di mana angka 1 mewakili perasaan sangat tidak setuju (strongly disagree) dan angka 7 mewakili perasaan sangat setuju (strongly agree), dengan total ertanyaan sebanyak 22. Berikut ini penjelasan mengenai ke-5 dimensi di atas, yaitu [10] [11]:

1. Tangibles (bukti terukur), menggambarkan fasilitas fisik, perlengkapan, dan tampilan dari personalia serta kehadiran para pengguna.

2. Reliability (keandalan), merujuk kepada kemampuan untuk memberikan pelayanan yang dijanjikan secara akurat dan handal.

3. Responsiveness (daya tanggap), yaitu kesediaan untuk membantu pelanggan serta memberikan perhatian yang tepat.

4. Assurance (jaminan), merupakan karyawan yang sopan dan berpengetahuan luas yang memberikan rasa percaya serta keyakinan.

5. Empathy (empati), mencakup kepedulian serta perhatian individual kepada para pengguna.

2.2. Teori-Teori Tentang Kepuasan Kerja

Ada tiga teori tentang kepuasan kerja, yaitu[12] [13]:

1. Teori ketidak sesuaian (Discrepancy)

2. Teori keadilan (Equity Theory)

3. Teori Dua Faktor (Two Factor Theory)

Teori ini mengukur kepuasan kerja seseorang menghitung selisih (disrepancy) antara apa yang seharusnya (should be) dengan kenyataan yang dirasakan. Kepuasan kerja seseorang bergantung pada selisih antara keinginan (expectation) dengan apa yang telah terpenuhi diperoleh melalui pekerjaannya.

\section{Metode Penelitian}

Metode penelitian :

1. Pada tahapan ini peneliti memastikan apa yang menjadi permasalahan pada objek yang diteliti yaitu Kantor Camat Dolat Rayat mengenai pelayanan yang diberikan pegawai terhadap masyarakat. 
2. Penentuan Permasalahan, dari identifikasi masalah pada langkah pertama akan dilanjutkan terhadap tahapan penentuan permasalahan. Pada penelitian ini, yang menjadi masalah adalah perilaku pegawai dalam melayani masyarakat yang ingin mengurus surat izin usaha.

3. Pengumpulan Data, pada tahapan ini penulis akan mengumpulkan data yang berhubungan dengan pelayanan terhadap masyarakat dengan beberapa tahapan yaitu Studi Pustaka, Observasi dan Wawancara.

a. Studi Pustaka, memperoleh data-data dengan cara mengutip dari beberapa bahan bacaan untuk memperoleh data dan informasi yang sifatnya teoritis yang dapat membantu penulis dalam menyelesaikan skripsi ini, penulis juga menggunakan buku-buku.

b. Observasi, aktifitas terhadap suatu proses atau objek dengan cara mengamati secara langsung terhadap pegawai yang melayani masyarakat yang akan mengurus izin usaha.

c. Wawancara, proses komunikasi lisan yang bertujuan menggali informasi tertentu dengan cara terstruktur dan dilakukan dua orang atau lebih. Dengan cara wawancara dan terjun langsung melakukan tanya jawab kepada pegawai yang bertugas di Kantor Camat Dolat Rayat kabupaten karo.

4. Metode Serqual, data yang sudah pada tahapan pengumpulan data akan dilanjutkan pada pengujian dengan menggunakan Metode Serqual, dimana metode ini merupakan salah satu metode yang dapat digunakan untuk melakukan rekomendasi terhadap suatu keputusan tertentu.

5. Perancangan, bagian ini proses perancangan mulai dari pembentukan UML (Unified Modelling Language) untuk menggambarkan alur perancangannya, selanjutnya perancangan antar muka sebagai bagian dari pengembangan aplikasi dan dilanjutkan dengan perancangan basis data.

6. Kode Program, kode program merupakan tahapan pembuatan aplikasi, pada penelitian ini yang akan dikembangkan adalah aplikasi dalam penentuan kepuasan masyarakat terhadap pelayanan berbasis visual basic.

7. Pengujian, tahapan pengujian merupakan tahapan output dari analisa dan perancangan yang telah dilakukan.

8. Implementasi, implementasi merupakan sebagai tahapan akhir yaitu penggunaan aplikasi yang sudah dikembangkan sebagai rekomendasi terhadap penentuan kepuasan terhadap pelayanan.

\section{Hasil dan Pembahasan}

Pada penelitian ini jenis instrumen penelitian kualitatif yang digunakan adalah kuesioner sebagai pedoman wawancara dan diskusi untuk merangkum serangkaian jawaban terhadap pelayanan masyarakat mengenai aspirasi atas sistem pelayanan yang telah dilaksanakan di Kantor Camat Dolat Rayat . Sedangkan jenis instrumen penelitian kuantitatif yang digunakan adalah kuesioner sebagai pedoman assessment. Proses penelitian dilakukan melalui penilaian para responden dengan wawancara dan praktek langsung yang dilaksanakan dengan memperhatikan kondisi lingkungan dan tujuan penelitian. Dalam menganalisa data penelitian ini digunakan metode diskriptif kualitatif-kuantitatif. Pada perumusan masalah mengenai sampai sejauh mana tingkat kepuasan masyarakat dalam hal pelayanan di Kantor Camat Dolat Rayat , maka digunakan Importance Performance Analysis atau analisa tingkat kepentingan dan kinerja kepuasan masyarakat. Berdasarkan hasil penilaian tingkat kepentingan dan hasil penilaian pelayanan maka akan dihasilkan suatu perhitungan mengenai tingkat kesesuaian antara tingkat kepentingan dan tingkat pelaksanannya di Kantor Camat Dolat Rayat. Penyebab potensial dari buruknya kualitas layanan suatu perusahaan jasa adalah karena adanya empat buah kesenjangan (gap) yaitu:

a. Gap antara persepsi manajemen akan ekspektasi konsumen dengan persepsi konsumen.

b. Gap antara persepsi manajemen dengan spesifikasi dari service quality.

c. Gap antara spesifikasi dari service quality dengan pelaksanaan service.

d. Gap antara pelaksanaan service dengan komunikasi eksternal.

e. Gap antara layanan yang diharapkan dengan layanan yang diterima.

Jika melihat data penyebarab responden berdasarkan pendidikan. Penelitian ini menemukan bahwa $(65 \%)$ responden memiliki latarbelakang pendidikan SLTA sederajat dari keseluruhan responden yang dipilih. Setelah didapatkan data, maka proses selanjutnya adalah melakukan uji kecukupan data . pengujian ini dilakukan untuk mengetahui jumlah data yang dikumpulkan cukup atau tidak. Perhitungan jumlah sampel minimum yang diperlukan adalah sebagai berikut.

$$
\begin{aligned}
& \mathrm{P}=\text { Proporsi benar }=120 / 125=0.96 \mathrm{Q}= \\
& \text { Proporsi salah }=5 / 125=0.04 \\
& n \geq \frac{\left(Z_{a} / 2\right) \cdot p \cdot q}{e^{2}}
\end{aligned}
$$


Analisis Customer Satisfaction Index (CSI), metode ini digunakan untuk menentukan tingkat kepuasan secara keseluruhan dengan pendekatan yang mempertimbangkan tingkat kepentingan dari atribut-atribut mutu jasa yang diukur. Pengukuran terhadap CSI diperlukan karena pertama, hasil dari pengukuran dapat digunakan sebagai acuan untuk menentukan sasaran-sasaran terhadap peningkatan pelayanan. Kedua, index diperlukan sebagai hal yang kontinu. Metode pengukuran CSI meliputi tahapan :

1. Menghitung importance weighting factors (faktor kepentingan terbobot), yaitu mengubah nilai rataan tingkat kepentingan menjadi angka presentase dari total nilai rataan tingkat kepentingan untuk seluruh atribut yang diuji, sehingga didapatkan total importance weighting factors $100 \%$.

2. Menghitung weighted score (skor terbobot), yaitu nilai perkalian antar nilai rataan tingkat kinerja/kepuasan masing-masing atribut dengan importance weighting factors masing-masing atribut.

3. Menghitung weighted total (total terbobot), yaitu menjumlahkan weighted score dari semua atribut mutu jasa.

4. Menghitung satisfaction index (indeks kepuasan), yaitu weighted total dibagi skala maksimal yang digunakan (skala maksimal 5), lalu dikalikan $100 \%$.

Analisis Tingkat Kepentingan (Importance-Performance Analysis), merupakan suatu metode penerapan untuk mengukur atribut menurut tingkat kepentingan dan kinerja atau tingkat kepuasan. Skala yang digunakan dalam pertanyaan kuesioner adalah skala Likert, dimana responden menyatakan tingkat setuju atau tidak setuju mengenai pertanyaan yang diajukan dalam kuesioner. Bobot dalam skala Likert dibuat ke dalam lima penilaian, yaitu :

a. Jawaban sangat penting atau sangat puas diberi bobot 81-100.

b. Jawaban penting atau puas diberi bobot 61-80.

c. Jawaban cukup penting atau cukup puas diberi bobot 41-60.

d. Jawaban tidak penting atau tidak puas diberi bobot 21-40.

e. Jawaban sangat tidak penting atau sangat tidak puas diberi bobot 0-20.

Setelah ini, yang dilakukan dalam analisis ini adalah menghitung berapa skor yang di dapat setelah mengumpulkan data atas kuesioner yang sudah di berikan kepada pelanggan. Analisis sistem yang dilakukan menggunakan metode UML (Unified Modeling Language). Analisis sistem ini menggunakan adaptasi metode Coad- Yourdon.

Tahap-tahap analisis sebagai berikut :

1) Identifikasi Aktor

2) Identifikasi use-case.

3) Pembuatan use-case diagram.

4) Pembuatan sequence diagram untuk memperjelas masing-masing usecase.

5) Pembuatan activity diagram untuk memperjelas use-case.

Variabel yang berdasarkan pada harapan (tingkat kepentingan) dan kinerja (tingkat kepuasan) masyarakat terhadap pelayanan di Kantor Camat Dolat Rayat . Dalam melayani masyarakat berdasarkan 5(lima) dimensi dalam metode servqual yaitu :

1. Tangibels (bukti fisik)

2. Reliability (kehandalan)

3. Responsiveness (daya tanggap)

4. Assurance (jaminan)

5. Empathy (empati)

Setelah data dikumpulkan lalu data tersebut diolah dan untuk selanjutnya dianalisis berdasarkan metode analisis yang digunakan dalam penelitian ini yaitu : analisis deskriptif, analisis regresi linier berganda dan analisis expectation dan performance matriks.

1. Analisis Deskriptif, analisis deskriptif mempunyai tujuan untuk menyajikan rangkuman statistik dalam bentuk tabulasi atau grafik. Disamping itu juga ditampilkan rangkuman statistik tentang latarbelakang responden yang meliputi faktor - faktor demografis.

2. Analisis regresi linier berganda, model ini digunakan untuk mengukur tingkat asosiasi antara variabel dengan kepuasan peserta, dengan model regresi berikut : $\mathrm{Y}=\mathrm{f}(\mathrm{X} 1, \mathrm{X} 2, \mathrm{X} 3, \mathrm{X} 4, \mathrm{X} 5)$. Sedangkan persamaan regresi secara sederhana sebagai berikut :

$\mathrm{Y}=$ Kepuasan masyarakat secara keseluruhan(variabel dependen). X1= Variabel independen tangibels

$\mathrm{X} 2=$ Variabel independen reliability

$\mathrm{X} 3=$ Variabel independen responsiveness $\mathrm{X} 4=$ Variabel independen assurance

$\mathrm{X} 5=$ Varibel independen empathy

3. Analisis expectation dan performance matriks. Digunakan untuk menemukan strategi dalam upaya 
meningkatkan kepuasan konsumen. Analisis ini menggunakan suatu diagram tersebut perusahaan dapat menentukan strategi yang diperlukan untuk meningkatkan performancenya berdasarkan tingkat kepentingan konsumen (costumer expectation). Kuesioner pada penelitian ini berisikan 10 pertanyaan tentang kualitas pelayanan. Jumlah kuesioner yang disebar pada masyarakat yang mengurus izin usaha di Kantor Camat Dolat Rayat sebagai berikut Jumlah yang disebarkan 150 responden kembali 120 responden, diolah 120 kuesioner. Identitas responden dari hasil kuesioner disusun berdasarkan jawaban responden,

Tingkat usia, jenis kelamin, dan tingkat pendidikan responden. Hasil pengolahan data menunjukan bahwa nilai rata - rata skor kualitas pelayanan yang dirasakan adalah 3,54. Skor berada dalam kategori agak tidak puas, jika dibanding dengan nilai rata - rata skor kualitas pelayanan yang dirasakan ternyata lebih rendah daripada yang diharapkan. Hal ini mengindikasikan adanya kesenjangan (gap). Rata - rata skor tertinggi diberikan untuk responsivenes dengan nilai 3,62 sementara nilai terendah diberikan pada dimensi empathy dengan nilai 3,44.

Tabel 1. Tingkat kepentingan masing-masing

\begin{tabular}{|c|l|c|c|}
\hline \multicolumn{4}{|c|}{ dimensi } \\
\cline { 1 - 4 } & \multicolumn{1}{|c|}{ Dimensi } & Nilai & Bobot (\%) \\
\hline 1. & Tangibels & 4,7 & 19,40 \\
\hline 2. & Reliability & 4,89 & 20,40 \\
\hline 3. & Assurance & 4,79 & 19,98 \\
\hline 4. & Empaty & 4,81 & 20,06 \\
\hline 5. & Responsiveness & 4,78 & 19,94 \\
\hline & Rata - rata & 4,80 & \\
\hline
\end{tabular}

Tabel 2. Kualitas pelayanan dipersepsikan menurut dimensi

\begin{tabular}{|c|l|c|}
\hline No. & \multicolumn{1}{|c|}{ Dimensi } & Nilai \\
\hline 1. & Tangibels & 3,54 \\
\hline 2. & Reliability & 3,61 \\
\hline 3. & Assurance & 3,49 \\
\hline 4. & Empaty & 3,44 \\
\hline 5. & Responsiveness & 3,62 \\
\hline & Jumlah & 3,54 \\
\hline
\end{tabular}

Tampilan Hasil Penilaian. Implementasi hasil penilaian ini adalah bagian penting dalam mengembangkan pelayanan dengan beberapa bagian yang penting, yaitu menampilkan hasil gap dari penilaian dari pengunjung.

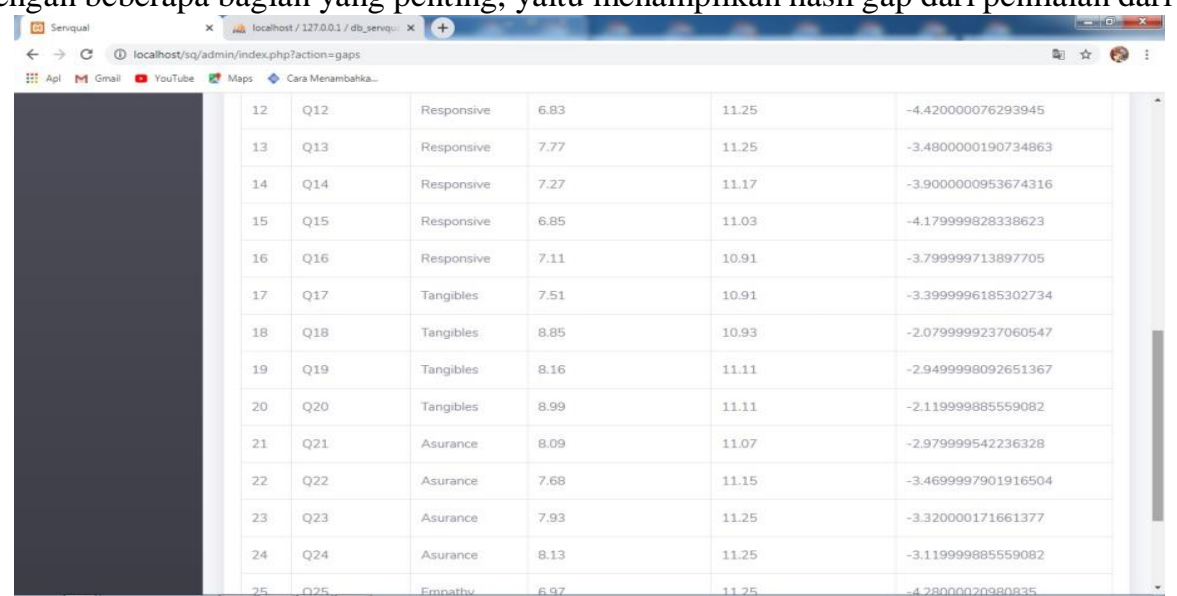

Gambar 1. Implementasi Hasil Penilaian

\section{Kesimpulan}

Kesimpulan dari penelitian :

1. Untuk menganalisa kepuasan pelayanan yang diberikan masyarakat dapat dipergunakan metode servqual dengan berdasarkan angka nilai global tunggal (single global rating).

2. Kriteria dan nilai bobot dari tingkat kepuasan tamu dapat ditentukan berdasarkan angka nilai global tunggal (single global rating) yaitu nilai point 1-5.

3. Untuk menginplementasikan metode servqual dilakukan dengan adanya interaksi dengan masyarakat. Baik secara langsung maupun melalui kuisioner yang diberikan. Agar dapat mengetahui tingkat kepuasan pada masyarakat di kantor camat dolat rakayat dalam meningkatkan mutu jasa pelayanan yang diberikan.

4. Perancangan aplikasi dapat dilaksanakan dengan menggunakan website agar pengunjung lebih gampang dalam memberikan penilaian, dimanapun pengunjung berada.

1. Pertanyaan yang terdapat didalam kuisioner dapat dikembangkan kembali sesuai dengan kebutuhan yang akan dikelola. 


\section{Daftar Pustaka}

[1] K. Jiwantara, A. Sutrisno, and J. S. C. Neyland, "Penyuluhan Bahasa Indonesia Praktis Di Balai Bahasa Provinsi Sulawesi Utara," 2012.

[2] A. S. R. Sinaga and J. Purba, "Penentuan Karyawan Lembur Dengan Metode Analytical Hierarchy Process ( Ahp )," vol. 1, no. 2, pp. 40-50, 2018.

[3] Y. Prananda, D. R. Lucitasari, and M. S. Abdul Khannan, "Penerapan Metode Service Quality (Servqual) Untuk Peningkatan Kualitas Pelayanan Pelanggan,” Opsi, vol. 12, no. 1, p. 1, 2019, doi: 10.31315/opsi.v12i1.2827.

[4] W. Wahyani, "Penerapan Metode Service Quality Untuk Menganalisis Kepuasan Pelanggan," p. 4, 2013, [Online]. Available: http://jurnal.itats.ac.id/wp-content/uploads/2013/06/PENERAPANMETODE-SERVICE-QUALITY-UNTUK-MENGANALISIS-KEPUASAN-PELANGGAN.pdf.

[5] S. S. Yuniar, S. Arijanto, and G. P. Liansari, "Usulan Perbaikan Kualitas Pelayanan Jasa Pengiriman Paket Berdasarkan Hasil Pengukuran Menggunakan Metode Service Quality ( Servqual ) Di PT.X*," J. Online Inst. Teknol. Nas., vol. 02, no. 02, pp. 98-109, 2014, [Online]. Available: https://ejurnal.itenas.ac.id/rekaintegra/article.

[6] M. Kholil, A. Agustina, and Tumin, "Analisis Kualitas Pelayanan dengan Metode Servqual untuk Meningkatkan Kepuasan Konsumen di PT. NGK Ceramics Indonesia," Jurnailimiah PASTI, vol. V, pp. 48-63, 2013.

[7] A. S. Sinaga, A. S. Sitio, and P. Sijabat, "Pengenalan Dasar Pengkodingan Secara Daring pada SMK Pemda Lubuk Pakam," Abdimas Univers., vol. 2, no. 2, pp. 95-99, 2020, doi: 10.36277/abdimasuniversal.v2i2.74.

[8] S. K. Dewi, “Analisis Kualitas Pelayanan dengan Metode Servqual dan Zone of Tolerance," J. Semin. Nas. Teknol. dan Rekayasa, vol. 3, no. 1, pp. 1-8, 2017.

[9] S. Nugrahani and R. Budirahaju, "Aplikasi Metode (Qfd) Untuk Meningkatkan Kualitas Layanan Permohonan Sim Pada Satlantas Kabupaten Jombang," EKUITAS (Jurnal Ekon. dan Keuangan), vol. 1, no. 4, 2018, doi: 10.24034/j25485024.y2017.v1.i4.2055.

[10] N. L. A. K. Y. Sarja, "Pengukuran Kepuasan Pengguna Sistem Informasi Dosen Menggunakan Metode Servqual," J. Sist. dan Inform., vol. 12, no. 2, pp. 19-25, 2018.

[11] R. T. Waruwu and A. Sindar, "SISTEM PAKAR MENENTUKAN JENIS GANGGUAN PERKEMBANGAN ANAK MENGGUNAKAN METODE CERTAINTY FACTOR,” vol. 2, no. 2, pp. 35-41, 2019.

[12] H. Winarno and T. Absor, "Analisis Kualitas Pelayanan Dengan Metode Service Quality (Servqual) Dan Importance Performance Analysis (Ipa) Pada Pt. Media Purna Engineering," J. Manaj. Ind. dan Logistik, vol. 1, no. 2, pp. 146-160, 2018, doi: 10.30988/jmil.v1i2.15.

[13] Muchamad Mustofa, Handoyo, and D. Ernawati, "ANALISIS TINGKAT KUALITAS PELAYANAN JASA DENGAN METODE SERVICE QUALITY ( ERVQUAL ) FUZZY DI PT . POS INDONESIA SIDOARJO Oleh Muchamad Mustofa ; Handoyo dan Dira Ernawati Prodi Teknik Industri, FTI- UPN "Veteran " Jatim," J. Ind. Eng. Manag., pp. 1-14, 2014. 